\title{
A INSTITUIÇÃO TOTAL COMO AGÊNCIA DE PRODUÇÃO DE SUBJETIVIDADE NA SOCIEDADE DISCIPLINAR ${ }^{1}$
}

\author{
TOTAL INSTITUTIONS AS AGENCY OF SUBJECTIVITY \\ PRODUCTION IN THE DISCIPLINARY SOCIETY
}

Sílvio José BENELLI

\begin{abstract}
RESUMO
A leitura de Goffman a partir das análises de Foucault pode nos proporcionar um enriquecimento fecundo na compreensão dos processos de produção de subjetividade na sociedade contemporânea e, de modo específico, no contexto das instituições totais, que estão longe de terem desaparecido. Consideramos que Goffman realiza uma modalidade de análise institucional que pode ser situada transitando entre os planos macro (ou molar) e micro dos fenômenos que ocorrem nos estabelecimentos fechados. Goffman analisa as práticas não-discursivas, e as articula com grande sutileza, fazendo os "detalhes" mais pitorescos e aparentemente insignificantes do cotidiano institucional falarem: percebemos, então, o plano microfísico das relações intra-institucionais mergulhando nas diferentes estratégias nas quais o poder se ramifica, circula, domina e produz saberes e sujeitos. Acreditamos que Goffman já apresenta o poder como uma relação dinâmica de estratégias sempre atuantes, presente em toda parte, em todos os lugares. Foucault, por sua vez, nos revela como são possíveis as instituições disciplinares e quais as razões de sua emergência. Ambos são excelentes referenciais para análises institucionais.
\end{abstract}

Palavras-chave: instituição total; subjetividade; análise institucional; Foucault, Michel; Gofman, Erving.

\begin{abstract}
Goffman's insights about Foucault's analyses can provide a considerable achievement about the subjectivity production processes knowledge in the
\end{abstract}

\footnotetext{
${ }^{1}$ Artigo elaborado a partir da dissertação de mestrado de autoria de S.J. Benelli, intitulada "Pescadores de Homens. A produção da subjetividade no contexto institucional de um Seminário Católico", sob a orientação do prof. Dr. Abílio da Costa-Rosa. Faculdade de Ciências e Letras, Universidade Estadual Paulista, Assis, 2003. Apoio: FAPESP.

${ }^{2}$ Curso de Filosofia, Faculdade João Paulo II. Caixa postal 1011, Jardim América, 17506-770. Marília, SP. Brasil. E-mail: <sjbewelli@yahoo.com.br>.
} 


\begin{abstract}
contemporary society and, mainly at total institutions context, where they are so present. We consider that Goffman's institutional analyses is between the macro (molar) and micro spheres of the phenomenon, that happen in closed institutions. He analyzes the non-discoursive practices, and subtlety articulates them, as the daily, apparently insignificant and bizarre "details" from institutional context makes us to realize the intra-institutional relations of microphysics plan, dipping into different strategies in which power itself branches, circulates, dominates and produces knowledges and subjects. We might say that Goffman has already introduced the idea of power as a dynamical relation of strategies always achieved at all parts and places. Foucault, reveals us how possible are disciplinary institutions and their reasons for emerging. They both are outstanding references to the institutional analyses.
\end{abstract}

Key-words: total institution; subjectivity; institutional analyses; Foucault, Michel; Gofman, Erving.

\section{ATUALIDADE DAS INSTITUIÇÕES TOTALITÁRIAS}

Estamos no início do século XXI, atravessando grandes transformações socioculturais produzidas pelo impacto do desenvolvimento tecnológico e da informática no cotidiano. Novas formas de relacionamento, de produção, de consumo, de produção de subjetividade se manifestam. As técnicas de vigilância, de punição, de controle social, de produção de sujeitos também estão se sofisticando a partir do suporte da tecnologia de ponta.

Mesmo nesse contexto de mudanças, as antigas instituições totalitárias não desapareceram da sociedade contemporânea. Pelo contrário, há uma florescente indústria funcionando ativamente no sistema prisional (Salla, 2000), nos novos pavilhões construídos para a Fundação para o Bem-Estar do Menor (FEBEM) (Guirado, 1986), nos inúmeros presídios que se espalham pelo interior do Estado de São Paulo. Nessa categoria de instituições ainda entram os hospitais psiquiátricos (Levinson \& Gallagher, 1971; Castel, 1978; Costa-Rosa, 1987; Goffman, 1987; Foucault, 1999a; Costa-Rosa, 2000; 2002), internatos escolares em geral (Hesse,1970; Rego, 1979; Hesse, 1980; Lautréamont, 1986; Musil, 1986; Perrone-Moisés, 1988; Pompéia, 1997; Benelli, 2002; 2003), colégios agrícolas com internato, asilos para idosos, orfanatos para crianças, quartéis e casernas militares, escolas para formação de policiais militares (Cruz, 1989), seminários católicos que acolhem adolescentes e jovens universitários em regime de internato para preparação para o sacerdócio (Cabras, 1982; Trevisan, 1985; Tagliavini, 1990; Rocha, 1991; Ferraz e Ferraz, 1994; Benelli \& Costa-Rosa, 2002), plataformas petrolíferas marinhas, casas que acolhem crianças em situação de risco, exército etc.

Considerando a permanência temporal de tais instituições, certamente espécimes ultrapassados, sobreviventes de séculos anteriores, entendemos que Goffman (1987) e Foucault (1999b) são dois referenciais estratégicos fundamentais para estudo e compreensão adequada dessas instituições. Elas ainda tendem a funcionar de modo clássico, tal como foram mapeadas por Goffman e Foucault, permanecendo alheias a sofisticações tecnológicas ou, em muitos casos, incorporando novidades informáticas sem maiores transformações estruturais. Esse instrumental teórico possibilita ainda uma intervenção profissional crítica nessas instituições, permitindo-nos um posicionamento ético congruente com a lógica da produção de subjetividade singularizada ao ocuparmos as brechas disponíveis na conjuntura atual.

Segundo Goffman (1987), as instituições totais se caracterizam por serem estabelecimentos fechados que funcionam em regime de 
internação, onde um grupo relativamente numeroso de internados vive em tempo integral. A instituição funciona como local de residência, trabalho, lazer e espaço de alguma atividade específica, que pode ser terapêutica, correcional, educativa etc. Normalmente há uma equipe dirigente que exerce o gerenciamento administrativo da vida na instituição. Acreditamos que Goffman (1987) tenha como programa justamente proceder a uma observação minuciosa do detalhe, buscando, ao mesmo tempo, um enfoque político dessas pequenas coisas do cotidiano, utilizadas para o controle e - diremos também - produção de subjetividade no contexto institucional (Benelli \& Costa-Rosa, 2002).

Consideramos que Goffman (1987) realiza uma modalidade de análise institucional que pode ser situada transitando entre os planos macro (ou molar) e micro dos fenômenos que ocorrem nos estabelecimentos fechados. Sua concepção explícita de poder é a de um poder essencialmente modelador, poder instaurado, repressivo e mutilador do eu em sua missão (res)socializadora. Isso parece ser o que Goffman apresenta numa primeira leitura. Mas depois de estudar algumas das contribuições de Foucault e da análise institucional (Costa-Rosa, 1987) relativas à produção da subjetividade no contexto institucional, uma leitura mais atenta de Goffman (1987) então nos permitiu encontrar também uma dimensão produtiva do poder: há nele uma microssociologia dos estabelecimentos totalitários que explicita toda uma tecnologia de poder altamente criativa.

Certamente podemos identificar opressores e oprimidos, caracterizados pela equipe dirigente e pelo grupo dos internados, os primeiros modelam e os segundos são objetos de procedimentos modeladores. Apesar de o binômio dominadoresdominados dar a impressão de que o poder seja uma instituição, estrutura ou certa potência que um grupo detém em prejuízo de outro, Goffman já revela, de certa forma, que poder é substancialmente relação e que são lugares que compõem a sua dinâmica.

Goffman (1987) descreve minuciosamente as reações de (contra)controle que os dois grupos antagônicos exercem um sobre o outro: há modelagem e resistências; vigilância permanente e recíproca; há lutas e conflitos nos planos macro e microfísicos. Goffman mapeia estratégias ostensivas de ataque e reações que se esboçam às vezes sutis, outras claramente defensivas ou sabotadoras. Mostra-nos como o grupo dos internados se defende dos esforços modeladores através de diversas táticas adaptativas e utilizando-se dos próprios recursos institucionais para construir um mundo pessoal contrário aos objetivos oficiais do estabelecimento. Há um clima de guerra permanente entre ambos os grupos antagônicos e, mesmo em cada grupo, há facções e disputas, relações de poder, forças em luta que compõem o cenário institucional.

Acreditamos que Goffman (1987), se não de modo explícito, já apresenta o poder como uma relação dinâmica de estratégias sempre atuantes, presente em toda parte, em todos os lugares. Tais lugares revelam-se como multiplicidade de relações de forças, em um jogo permanente que, através de lutas e enfrentamentos declarados ou velados, incessantes, transforma, reforça, inverte, origina apoios, pontos de resistência.

Contudo, sentimos a ausência de um campo no qual situar as análises de Goffman (1987) que nos permitisse localizar as "instituições totais" dentro de uma evolução geral das instituições. Esse campo de referências históricas que falta em Goffman, nós o encontramos na obra de Michel Foucault, no que se refere a uma história do desenvolvimento das instituições que se ocupam com presos, loucos, estudantes e doentes (Foucault, 1984, 1999a, 1999b). Como já dissemos, parece-nos que Goffman não tem uma percepção apenas repressiva do poder, enquanto que Foucault apresenta mais claramente o poder como portador de uma positividade produtiva, tanto de saberes quanto de sujeitos.

\section{A SOCIEDADE DISCIPLINAR}

Foucault (1999b, p.118), ao estudar o funcionamento do poder nas sociedades moder- 
nas, afirma que procedimentos disciplinares já existiam há muito tempo nos conventos, no exército, nas oficinas. "Mas as disciplinas se tornaram no decorrer do século XVII e XVIII formas gerais de dominação". Elas seriam uma sofisticação da tecnologia conventual monástica que, apesar de implicar a obediência a um superior, tinha como objetivo principal o aumento do autodomínio.

O momento histórico das disciplinas é o momento em que nasce uma arte do corpo humano, que visa não unicamente 0 aumento de suas habilidades, nem tampouco aprofundar sua sujeição, mas a formação de uma relação que no mesmo mecanismo o torna tanto mais obediente quanto mais é útil, e inversamente (Foucault, 1999b, p.119).

O corpo humano foi então submetido a uma "anatomia política" e igualmente a uma "mecânica do poder" que o esquadrinha, desarticula, recompõe. A disciplina fabrica corpos submissos, exercitados, fortes, aumenta sua aptidão e ao mesmo tempo sua dominação. Uma "microfísica" do poder produz um investimento político e minucioso do corpo, tendendo, desde o século XVII, a cobrir todo o âmbito social.

Uma observação minuciosa do detalhe, e ao mesmo tempo um enfoque político dessas pequenas coisas, para controle e utilização dos homens. Sobem através da era clássica, levando consigo todo um conjunto de técnicas, todo um corpo de processos e de saber, de descrições, de receitas e dados. E desses esmiuçamentos, sem dúvida, nasceu o homem do humanismo moderno (Foucault, 1999b, p.121).

\section{A instituição total como organização implementada pelo poder disciplinar}

Vamos apresentar o recenseamento que Foucault fez dos diversos procedimentos e técnicas que constituem o poder disciplinar e seus efeitos microfísicos, implementados nas instituições totais.
Inicialmente, a tecnologia disciplinar promove a distribuição dos indivíduos no espaço, utilizando diversos procedimentos: o enclaustramento (baseado no modelo conventual); o quadriculamento celular e individualizante ("cada indivíduo no seu lugar; e, em cada lugar, um indivíduo"); a regra das localizações funcionais (vigiando ao mesmo tempo em que cria um espaço útil); a classificação e a serialização (individualizando os corpos ao distribuí-los e fazendo-os circular numa rede de relações). Assim, essa tecnologia, organizando celas, lugares, fileiras, cria espaços altamente complexos, incidindo nos planos arquitetônico, funcional e hierárquico:

São espaços que realizam a fixação e permitem a circulação; recortam segmentos individuais e estabelecem ligações operatórias; marcam lugares e indicam valores; garantem a obediência dos indivíduos, mas também uma melhor economia do tempo e dos gestos (Foucault, 1999b, p.127).

Em segundo lugar, a tecnologia disciplinar visa a um minucioso controle da atividade. Fundamental para esse controle é a administração do tempo através do estabelecimento do horário, tempo estritamente organizado também a partir dos moldes monásticos, mas então afinados de modo radical: contam-se os quartos de hora, minutos, segundos. Regularidade, exatidão e aplicação são características fundamentais do tempo disciplinar.

Investe-se ainda numa elaboração temporal do ato através de uma decomposição precisa dos gestos e movimentos, visando ajustar o corpo a imperativos temporais. Assim, "o tempo penetra o corpo, e com ele todos os controles minuciosos do poder" (Foucault, 1999b, p.129). O controle disciplinar põe o corpo e o gesto em perfeita e absoluta correlação, pois "um corpo bem disciplinado é a base do gesto eficiente" (Foucault, 1999b, p.130). Procede-se também a uma codificação instrumental do corpo que tem como objeto não a subtração, mas a síntese, ligando o indivíduo ao aparelho de produção.

O tempo monástico era fundamentalmente negativo, baseado no princípio da não-ociosidade. 
O tempo disciplinar, pelo contrário, visa à utilização exaustiva: baseia-se no princípio de uma utilização teoricamente crescente do tempo, intensifica o uso do mínimo instante, buscando extrair sempre mais forças úteis. O máximo de rapidez deve encontrar o máximo de eficiência.

À medida que o corpo vai se tornando alvo de novos mecanismos de poder, oferece-se também a novas formas de saber: logo o comportamento e as exigências orgânicas vão lenta e gradualmente substituir uma física algo tosca dos movimentos:

O corpo, do qual se requer que seja dócil até em suas mínimas operações, opõe e mostra as condições de funcionamento próprias de um organismo. O poder disciplinar tem por correlato uma individualidade que não só é analítica e 'celular', mas também natural e 'orgânica' (Foucault, 1999b, p.132).

Em terceiro lugar, há um aperfeiçoamento do "programa" da busca de perfeição místicoreligiosa, que pretendia levar um indivíduo à santidade, sob a direção de um mestre, constituída por uma vida ascética organizada em tarefas com níveis crescentes de dificuldade. $O$ poder disciplinar é genético, organiza gêneses: divide a duração em segmentos, organiza seqüências de acordo com um esquema analítico, institui uma prova de qualificação no final do processo e estabelece séries de séries.

O "exercício" é a técnica por excelência pela qual se impõe aos corpos tarefas ao mesmo tempo repetitivas, diferentes e graduadas. Já não visa à salvação da alma, mas foi transformado numa tecnologia política do corpo e da duração, num processo de sujeição interminável.

Finalmente, a tecnologia disciplinar visa à composição das forças, reparte os corpos, extrai e acumula o tempo dos mesmos, buscando também compor forças para obter um aparelho eficiente. "O corpo se constitui como peça de uma máquina multissegmentar" (Foucault, 1999b, p.139). A disciplina combina ainda séries cronológicas para formar um tempo composto de modo a extrair a máxima quantidade de forças de cada um e combiná-las num resultado ótimo; através da arregimentação, todos os indivíduos cumprem suas tarefas em uníssono, sob um sistema preciso de comando.

Foucault (1999b, p.141) sintetiza a produção que o poder disciplinar efetua a partir dos corpos que controla: uma individualidade caracterizada como celular (através do jogo da repartição espacial); orgânica (pois codifica formalmente as atividades); genética (ao acumular um tempo segmentado e serializado) e combinatória (pela composição das forças). A tecnologia disciplinar - aperfeiçoada, sobretudo, a partir da matriz conventual (Benelli, 2002a) - tende a atravessar as diversas instituições que compõem o corpo social, incidindo num nível propriamente capilare microfísico do tecido social. Através do processo descrito acima, o poder disciplinar constrói uma sociedade disciplinar, adestrando, produzindo coletivamente corpos individualizados e dóceis. Trata-se de uma modalidade de poder produtivo, e não essencialmente restritivo, mutilador ou repressivo, que liga as forças para multiplicá-las e utilizá-las em sua totalidade, apropriando-se delas ainda mais e melhor. A ação do poder disciplinar é essencialmente produção de subjetividade moderna.

\section{Instrumentos técnicos para o adestramento disciplinar}

A disciplina 'fabrica' indivíduos; ela é a técnica de um poder que toma os indivíduos ao mesmo tempo como objetos e como instrumentos de seu exercício. "(...) O sucesso do poder disciplinar se deve sem dúvida ao uso de instrumentos simples: o olhar hierárquico, a sanção normalizadora e sua combinação num procedimento que the é específico, o exame" (grifo meu) (Foucault, 1999b, p.143). Visibilidade total e irrestrita é a nova estratégia utilizada pelo poder disciplinar a fim de realizar o controle - sem uso da violência ostensiva - para o exercício de uma vigilância produtiva. Cria-se um dispositivo, "observatório" que obriga pelo jogo do olhar um aparelho onde técnicas óticas efetuam manobras de poder: olho do poder que vigia, 
produz, torna inteiramente visíveis os indivíduos sobre os quais incide.

O acampamento militar é o diagrama de um poder que age pelo efeito de uma visibilidade geral. Durante muito tempo encontraremos no urbanismo, na construção das cidades operárias, dos hospitais, dos asilos, das prisões, das casas de educação, esse modelo do acampamento ou pelo menos o princípio que o sustenta: o encaixamento espacial das vigilâncias hierarquizadas (Foucault, 1999b, p.144).

Há uma problematização da arquitetura no sentido de tornar visíveis e observáveis os que nela se encontram. A arquitetura passa assim a ser um operador que visa a transformação dos indivíduos: sua incidência sobre aqueles que abriga produz um domínio sobre seu comportamento, propaga até eles efeitos de poder, expõem-nos ao saber e ao conhecimento, modifica-os.

Assim é que o hospital-edifício se organiza pouco a pouco como instrumento de ação médica (...) um operador terapêutico. Como a escola-edifício deve ser um operador de adestramento, (...) um aparelho de vigiar (Foucault, 1999b, p.145).

Há uma objetivação progressiva e um quadriculamento detalhado dos comportamentos individuais:

As instituições disciplinares produziram uma maquinaria de controle que funcionou como um microscópio do comportamento; as divisões tênues e analíticas por elas realizadas formaram, em torno dos homens, um aparelho de observação, de registro e de treinamento (Foucault, 1999b, p.145).

Um estabelecimento circular, o Panopticon de Bentham (Foucault, 1984; 1999b; 1999c), capacitaria perfeitamente que o olho do poder vigiasse efetiva e permanentemente tudo, ao mesmo tempo fonte de luz e ponto de convergência do que deve ser sabido. A estrutura piramidal permite a organização de uma vigilância escalonada: forma uma rede sem lacunas, mutiplicando seus degraus, de forma discreta, potencializando os efeitos do dispositivo disciplinar. A decomposição hierárquica, piramidal, do poder disciplinar aumenta sua sutileza e sua função produtiva: tornar a vigilância mais escalonada é torná-la mais funcional, nas diversas instituições disciplinares.
A vigilância hierárquica
organiza-se como um poder múltiplo, auto- mático e anônimo (...) seu funcionamento é de uma rede de relações de alto a baixo, mas também até um certo ponto de baixo para cima e lateralmente; essa rede "sustenta" o conjunto, e o perpassa de efeitos de poder que se apóiam uns sobre os outros: fiscais perpetuamente fiscali- zados (...) funciona como uma máquina (...) é o aparelho inteiro que produz "poder" e distribui os indivíduos nesse campo permanente e contínuo (Foucault, 1999b, p.148).

Poder "discreto" que funciona silencioso e permanentemente, poder "indiscreto" onipresente, onisciente, que tudo vê, tudo sabe, sempre atento, alerta, esquadrinhando e controlando continuamente os indivíduos, através de "olhares calculados" em jogos ininterruptos, todos vigiam a todos:

Graças às técnicas de vigilância, a física do poder, o domínio sobre o corpo se efetua segundo as leis da ótica e da mecânica, segundo um jogo de espaços, de linhas, de telas, de feixes, de graus, e sem recurso, pelo menos em princípio, ao excesso, à força, à violência. Poder que é em aparência, menos "corporal" por ser mais sabiamente "físico" (Foucault, 1999b, p.148).

\section{Microtribunal institucional}

Um mecanismo penal autônomo funciona no interior das diversas instituições disciplinares, possuidor de um privilégio auto-outorgado de fazer justiça, de impor leis próprias, elaborar catálogo de delitos específicos, criar instâncias de julgamento e formas particulares de sanção. Uma ordem jurídica se inscreve no cerne dessas instituições: os regulamentos obrigam tanto quanto a sanção legal no campo jurídico, sanção 
terapêutica no hospital, pedagógica na escola, reeducativa na prisão.

Uma micropenalidade repressiva atua sobre os mais ínfimos comportamentos e detalhes de conduta. Todo um conjunto de processos sutis é organizado num plano que vai do castigo físico, passando por privações calculadas até as pequenas humilhações. Aquele que se afasta ou não se submete à norma receberá a sanção que se destina a fazê-lo retornar ao interior da norma. Goffman (1987, p.24) apresenta os "processos de mortificação do eu" como processos padronizados que expressam e exemplificam o funcionamento da sanção normalizadora.

O "circuito", descrito por Goffman (1987, p.40) "como uma perturbação na relação usual entre o ator individual e seus atos", permite penalizar os aspectos mais tênues do comportamento, inserindo o indivíduo num universo punitivo e persecutório. No "circuito", uma agência cria uma resposta defensiva no internado e depois utiliza essa resposta para seu ataque seguinte. O indivíduo descobre que sua resposta protetora diante de um ataque a sua pessoa falha na situação, pois não se pode defender da forma usual ao tentar estabelecer uma distância entre si mesmo e a situação mortificante.

Goffman (1987, p.41) indica também a tiranização do indivíduo através de um processo de infantilização social que retira dele sua autonomia, liberdade de ação e capacidade de decisão, perturbando decididamente sua capacidade de autodeterminação. As menores partes de sua atividade ficam sujeitas a regulamentos e julgamentos da equipe dirigente. A vida do internado é constantemente vigiada e sancionada do alto, sobretudo no período inicial de sua estada, antes de ele se acostumar e se submeter aos regulamentos sem pensar. Cada especificação normativa da conduta priva o indivíduo da oportunidade de equilibrar suas necessidades e objetivos de maneira pessoalmente eficiente, violentando a autonomia pessoal. O controle minucioso é extremamente limitador numa instituição total. Além da tiranização, o internado também está submetido ao processo de arregimentação (Goffman, 1987, p.44), que indica a obrigação de executar a atividade regulada em uníssono com grupos de outros internados.

Também existe um sistema de autoridade escalonada (Goffman, 1987, p.45): qualquer pessoa da equipe dirigente tem o direito de impor disciplina a qualquer dos internados, o que aumenta claramente a possibilidade de sanção. No mundo externo, o adulto normalmente está sob a autoridade de um único superior no trabalho, sob a autoridade do cônjuge na vida doméstica e a autoridade escalonada da polícia não é onipresente. Os internados podem viver, sobretudo os novatos, aterrorizados e cronicamente angustiados quanto à desobediência das regras e suas conseqüências pela onipresença da autoridade escalonada e pelos regulamentos difusos.

De acordo com Foucault (1999b, p.149), o objeto de punição disciplinar é o desvio do que prescreve o regulamento, lei que programa o funcionamento institucional. A inobservância, a inadequação à regra, o afastamento da mesma são áreas de abrangência da penalidade disciplinar, que é essencialmente jurídica. Para corrigir os desvios, o castigo disciplinar deve ser fundamentalmente corretivo, baseado no exercício repetido como condição de um aprendizado intensificado. Castigar é então punir com exercícios numa insistência redobrada à norma.

Elabora-se uma microeconomia baseada no sistema de gratificação-sanção: uma qualificação dos comportamentos e desempenhos como bons ou maus, positivos ou negativos, que passam a ser mensuráveis por notas ou pontos, quantificados, contabilizados. "Uma contabilidade penal, constantemente posta em dia, permite obter o balanço positivo de cada um" (Foucault, 1999b, p.151). O passo seguinte é a integração dessa microeconomia penal perpétua no saber, no conhecimento dos indivíduos: as notas indicam a natureza dos indivíduos bons e maus, os alunos "fortes" e "fracos", num processo de diferenciação individualizante (cf. Pompéia, 1997, p.75: "o Livro das notas"). O comportamento geral do indivíduo é sempre tomado como indicador de patologia ou de convalescença (Goffman, 1987). 
O sistema microeconômico de gratificaçãosanção é denominado por Goffman (1987, p.49) de "sistema de privilégios" que inclui os "ajustamentos primários", "ajustamentos secundários", prêmios e castigos. A penalidade perpétua, nas instituições disciplinares, normaliza os indivíduos, diferenciando-os uns dos outros com base no critério da norma: "o que se deve fazer funcionar como base mínima, como média a respeitar ou como o ótimo de que se deve chegar perto" (Foucault,1999b, p.152).

No regime disciplinar, o objetivo da punição não é obter a expiação nem promover a repressão, afirma Foucault. Ela produz sujeitos normalizados ao relacionar os atos, os desempenhos, os comportamentos singulares a um conjunto normativo ideal que funciona ao mesmo tempo como parâmetro de comparação, espaço diferenciador e princípio de uma regra a seguir.

O parâmetro normativo funciona coagindo a uma conformidade a realizar, traçando limites, estabelecendo diferenças, criando fronteiras entre o normal e o anormal. Assim, o poder da norma se baseia em um conjunto de fenômenos observáveis, na especificação de atos em um certo número de categorias gerais, fazendo funcionar a oposição binária do permitido e do proibido, produz diferenciação e classificação, hierarquização e distribuição de lugares. A regulamentação normalizante não produz homogeneidade, ela individualiza, mede desvios, determina níveis, fixa especialidades, torna úteis as diferenças, ajustando-as entre si, introduz toda a gradação das diferenças individuais.

\section{O exame como instrumento de sanção normalizadora institucional ${ }^{3}$}

As técnicas da vigilância escalonada e da sanção que normaliza se unificam na produção da tecnologia do exame, que produz efeitos de controle normalizante e uma vigilância que permite qualificar, classificar e punir. Técnica sofisticada na qual poder e saber se superpõem, se imbricam profundamente. "No coração dos processos de disciplina, ele manifesta a sujeição dos que são percebidos como objetos e a objetivação dos que se sujeitam" (Foucault,1999b, p.154), mecanismo no qual relações de poder permitem obter e constituir campos de saber.

O hospital, a escola e o exército se organizaram como "aparelhos de examinar" contínuos: a visita do médico ao doente no hospital e o exame escolar funcionaram como limiar epistemológico para a assunção científica da medicina e da pedagogia. Da mesma forma, inspeções permanentes no exército permitiram o desenvolvimento de um grande saber tático. "O exame supõe um mecanismo que liga um certo tipo de formação de saber a uma certa forma de exercício do poder" (Foucault,1999b, p.156).

Segundo Foucault, o exame inverte a economia da visibilidade no exercício do poder: o poder disciplinar, ao exercer-se torna-se invisível, mas os objetos aos quais se aplica são submetidos a um princípio de visibilidade obrigatória. "É o fato de ser visto sem cessar, de sempre poder ser visto, que mantém o sujeito indivíduo disciplinar" (Foucault,1999b, p.156). O exame é a técnica pela qual o poder capta os indivíduos num mecanismo de objetivação, organiza objetos no espaço que domina, até em seus graus mais baixos.

Além disso, o exame também insere a individualidade num campo documentário: relatórios, prontuários, fichas, arquivos e pastas pessoais e dossiês são alimentados com detalhes que captam e fixam os sujeitos numa rede de anotações. "Os procedimentos de exame são acompanhados imediatamente de um sistema de registro intenso e de acumulação documentária" (Foucault,1999b, p.157). Goffman (1987, p.25) também apresenta a prática da realização dos "processos de admissão" e do "dossiê" pessoal.

A escrita disciplinar também possui efeitos individualizantes e normalizantes: ela descreve e analisa o objeto indivíduo, mantendo-o em seus traços singulares, submetido a um saber permanente. É aí que Foucault localiza o nascimento

\footnotetext{
${ }^{3}$ Os destaques em itálico desta seção são de Foucault (1999b).
} 
das ciências humanas, elaboradas no bojo de relações de saber/poder que realizam a coerção dos corpos, gestos e comportamentos. Trata-se de uma dominação produtiva, que não opera por subtração ou repressão, mas visa a diferenciação e a multiplicidade útil dos sujeitos.

Por fim, o exame, cercado por esta técnica da documentação, transforma o indivíduo em um "caso", objeto de conhecimento e de poder, ao mesmo tempo. "O 'caso' (...) é o indivíduo tal como pode ser descrito, mensurado, medido, comparado a outros e isso em sua própria individualidade; e é também o indivíduo que tem que ser treinado ou retreinado, tem que ser classificado, normalizado, etc." (Foucault,1999b, p.159). Goffman (1987, p.70) também apresenta o "registro de caso" que vai sendo produzido ao longo da carreira do internado.

O exame encontra-se no centro mesmo dos processos que individualizam os sujeitos como efeito e objeto de poder e de saber. "Na verdade, o poder produz; ele produz realidade; produz campos de objetos e rituais de verdade. O indivíduo e o conhecimento que dele se pode ter se originam nessa produção" (Foucault,1999b, p.161).

\section{A instituição total como agência de produção de subjetividade}

Goffman (1987) diz o que são, como funcionam e indica o que produzem as instituições totais. Foucault (1984, 1999a, 1999b), por sua vez, nos revela como são possíveis as instituições disciplinares e quais as razões de sua emergência, além de apontar para sua futura obsolescência e desaparecimento. Finalmente, será Deleuze (1992) aquele que nos revela a emergente sociedade de controle como superação da sociedade disciplinar.

Curiosamente, como vimos, Foucault (1999b) nos apresenta uma sociedade disciplinar sem brechas, na qual a resistência ao poder parece impossível. Movimentos de resistência e mesmo sua possibilidade parecem ausentes no horizonte do livro "Vigiar e Punir". Será em outros momentos que Foucault $(1982,1999 c)$ abordará 0 assunto.
As análises de Goffman (1987) são extremamente agudas quando estudam as formas da organização do dispositivo institucional. Se ele não chega a articular uma microfísica do poder no contexto institucional e social, como faz explicitamente Foucault, isso aparece numa leitura atenta em sua investigação do manicômio, da prisão e do convento. Goffman não pode conceituar o poder como relações de força em guerra, entretanto, é assim que sua análise o revela: produzindo no nível microfísico exatamente do modo como o poder opera, para além dos limites teóricos e conceituais do autor.

Ao estudar as relações intra-institucionais, ele oscila entre os planos molares e microfísicos: estabelece polaridades de poder e não-poder, nas quais, aparentemente, este seria privilégio de um grupo minoritário que infligiria a outro mais numeroso as conseqüências do abuso do poder; mas também apresenta um poder que se estende como uma rede de pontos, relações móveis, resistências, efeitos repressivos, coercitivos e, inclusive, produtivos. Estão explícitas as mais diversas estratégias anônimas de poder. Das práticas não-discursivas emergem concepções do objeto institucional e de quais são os meios e instrumentos utilizados para trabalhá-lo. Normalmente, essa teoria e técnica da prática (pois, "na prática, a teoria é outra") costumam estar em franca contradição e conflito com o discurso institucional oficial.

Goffman (1987) analisa as práticas não-discursivas, o não-dito institucional, mas que é claramente visível (e não oculto) e, portanto, dizível: ele os articula com grande sutileza. Goffman faz os "detalhes" (Foucault, 1999b, p.120) mais pitorescos e aparentemente insignificantes do cotidiano institucional falarem: percebemos então o plano microfísico das relações intra-institucionais superando a pura e simples dimensão organogramática (molar) e mergulhando nas diferentes estratégias nas quais o poder se ramifica, circula, domina e produz.

Consideramos a subjetividade como uma produção eminentemente social e, portanto, coletiva. No contexto institucional, ela é produzida na intersecção das práticas discursivas (imaginá- 
rias e simbólicas) e das práticas não-discursivas. Podemos dizer que o discurso subjetiva tanto quanto as práticas. Geralmente, o discurso oficial se apresenta lacunar (ideológico) e as práticas trazem embutidas, nas suas próprias condições de possibilidade, um outro discurso que, apesar de não-dito, é perfeitamente visível e extremamente efetivo quanto à produção de subjetividade.

As práticas sociais não-discursivas podem ser detectadas nos detalhes do cotidiano do funcionamento institucional: são aqueles aspectos realmente concretos do modo como se fazem as diversas atividades, incluem ainda o aspecto arquitetônico, o organograma formal e informal e o mobiliário. Estudando o modo concreto através do qual se executam as tarefas, podemos deduzir toda uma teoria e uma técnica relativas ao objeto institucional: as práticas embutem conceitos, definições, procedimentos e instrumentos para manuseio do objeto. Trata-se de fatos observáveis, visíveis, que não estão necessariamente ocultos. Eles tendem a não ser percebidos por seu caráter demasiado óbvio e por serem recobertos pelo discurso lacunar, que costuma mascará-los.

Vimos Foucault demonstrar como o poder produz práticas das quais extrai um saber sobre o objeto ao qual ele se aplica. Há uma íntima relação entre o exercício do poder e a produção de saber. Relações de poder enformam práticas das quais emergem discursos, num procedimento circular produtivo, do qual emergem indivíduos, sujeitos, subjetividade.

Na sociedade disciplinar, alguém exerce um poder sobre o sujeito, vigiando-o: o professor sobre os alunos; o médico sobre os doentes; o psiquiatra sobre os loucos; o guarda sobre os presidiários. Enquanto exerce esse poder, vigia e ao mesmo tempo produz um saber a respeito daqueles que estão sob sua jurisdição. Esse saber é caracterizado pela norma, é um saber normatizador que se ordena em termos daquilo que é estabelecido como normal ou não, correto ou incorreto, daquilo que se deve ou não fazer. $\mathrm{Da}$ prática desse poder/saber, vão surgir as ciências humanas: psiquiatria, psicologia, sociologia, pedagogia etc.
É inegável a implantação do panoptismo na arquitetura das prisões, escolas, fábricas, hospitais etc. Trata-se de uma arquitetura de vigilância que permite a um único olhar percorrer o maior número de indivíduos, rostos, corpos, comportamentos, celas. Não se trata mais de uma arquitetura do espetáculo, como era a da sociedade grega, ou dos rituais religiosos nos quais os gestos e as palavras de um único indivíduo podiam ser presenciados por grandes audiências.

O panoptismo implementa e estrutura diversas instituições contemporâneas: saúde, educação, religião etc., que por sua vez se encarnam em estabelecimentos como hospitais, escolas, igrejas etc. Ele funciona no próprio cotidiano desses estabelecimentos que enquadram a vida e os corpos dos indivíduos no nível mesmo da existência individual, tal como descrito por Foucault (1999b) e por Goffman (1987), por mais antiquado que isso possa parecer. O saber que se forma a partir da observação dos indivíduos, da sua classificação, registro, análise e comparação dos comportamentos, caracteriza-se como um saber tecnológico, típico a todas as instituições de seqüestro, e que está na base da construção das diversas ciências humanas. São jogos de poder e de saber - poder polimorfo e saber que efetua intervenções - exercidos simultaneamente nessas instituições que transformam o tempo e a força de trabalho, integrando o homem na produção.

Tal como foi instaurado no século XIX, o capitalismo penetrou profundamente na existência humana e um poder político realizou uma série de operações complexas através das quais ela foi ligada ao aparelho de produção. A partir daí, enunciados que afirmam que a essência do homem é o trabalho começaram a surgir e a operar efeitos de verdade. O regime capitalista elaborou um conjunto de técnicas políticas permeadas de poder que sujeitou o homem ao trabalho. Foi criado todo um conjunto de técnicas que incidiram diretamente no corpo e no tempo humanos, transformados em tempo e força de trabalho, utilizados na produção de mais-valia. Foi uma rede de poderes microscópicos que, intervindo sobre a existência humana, fixaram o 
homem ao aparelho de produção, tornando-o trabalhador, agente de produção. Não há produção de mais-valia sem esse poder capilar e microfísico.

A sociedade capitalista é caracterizada por relações de produção específicas que, por sua vez, são determinadas por estas relações de poder microfísico e por formas de funcionamento de saberes que plasmaram as chamadas ciências humanas. Assim, poder e saber encontram-se mutuamente implicados, não se superpõem às relações de produção, mas estão profundamente imbricados na própria constituição delas. As ciências humanas, o homem como objeto da ciência, têm como possibilidade para seu surgimento a própria gênese e construção da sociedade disciplinar, que implementou em seus dispositivos as instituições de seqüestro, onde espaços e equipamentos de controle permitem a atualização da maquinaria do Panopticon (Foucault, 1984; 1999b; 1999c), multiplicando nelas saberes sobre o indivíduo, a normalização e a correção.

Foucault (1984), utilizando a política da verdade como instrumento para sua análise histórica da origem da atual sociedade disciplinar, conclui que as relações de força e relações políticas são as condições de possibilidade para a formação de um certo número de domínios de saber. As condições políticas e econômicas da existência não são um obstáculo ideológico para o sujeito do conhecimento, mas são as condições nas quais se formam, se constituem os sujeitos de conhecimento e as relações de verdade.

O campo social é organizado segundo um paradigma bélico da luta ou da guerra de acordo com Foucault (1999c), e todas as práticas sociais comportam sempre a dimensão de ações estratégicas. O poder é o elemento central em qualquer sistema social, que se exerce de modo estratégico. Aquilo que se mostra como um ordenamento social é apenas um arranjo momentâneo, mais do que um bloco sólido e permanente. Trata-se somente do resultado atual numa luta constante e nos diversos empregos do poder. Nessa luta, o poder não é propriedade de alguns, e os demais nunca estão totalmente dele destituídos.

Foucault (1982) afirma que a perspectiva de que o poder seja algo que se localiza somente no aparelho de Estado está equivocada. O poder estatal funciona atravessado por um sistema de poderes que o compõem e ultrapassam. Ele tampouco é apenas um instrumento do modo de produção dominante, pois foi justamente o poder disciplinar moderno que, ao submeter o tempo ao imperativo da produção (Foucault, 1984), possibilitou a emergência do Modo de Produção Capitalista (MPC). O poder não deve ser entendido como agente basicamente repressor, mas Foucault o apresenta como pleno de uma função produtiva e criadora tanto de saberes quanto de sujeitos.

Ao investigar o surgimento e constituição da sociedade moderna, Foucault se pergunta pelas técnicas de implementação e exercício de poder que estão na sua base. Para produzir sujeitos não bastam o uso da violência, valores morais, normas interiorizadas ou influência ideológica. Foucault vai buscar as técnicas de poder modernas que se concentraram no corpo, no saber e nas normas. A tecnologia moderna do poder se caracteriza por uma canalização produtiva de forças submetidas ao adestramento disciplinar e a uma rotinização do agir em direção a padrões normativos fixos, a partir do que se constrói uma noção de "normalidade".

O primeiro lugar de exercício do poder moderno não é o plano cultural, mas os corpos em sua própria materialidade concreta, física e manifestações vitais. É como uma "microfísica" que as modernas técnicas de poder se exercitam sobre a padronização e adestramento dos processos de movimento do corpo, visando disciplinar os movimentos motores dos indivíduos em direção a atividades produtivas, numa busca de extrair sua máxima eficácia. Além da dimensão do corpo do indivíduo, o poder investe também no controle e desenvolvimento do comportamento biológico das populações, na estatística dos seus níveis de natalidade, mortalidade, morbidade e saúde (Foucault, 1982). 
Mas essas técnicas de poder modernas desenvolvem sua eficiência máxima quando se organizam sob a forma de saberes, num ciclo regular. A tecnologia do poder se formula em regras de descobrimentos científicos relativos aos corpos e à vida. São nos estabelecimentos sociais, tais como clínica, prisão, hospital, escola, manicômio, fábrica etc.; que se constroem discursos científicos e profissionais, saberes conjugados com poderes. Poder produz saber $\mathrm{e}$ vice-versa, pois não existe saber que não esteja alicerçado em relações de poder que erigem as formas políticas da verdade ao longo da história.

Desse modo, Foucault (1982) construiu uma grade de análise que denominou de dispositivo, com a qual pretende dar conta das conexões entre saber/poder: um dispositivo engloba materiais heterogêneos, o dito e o não-dito. $A$ partir desses componentes díspares, o genealogista pode estabelecer um conjunto de relações flexíveis, reunindo-as num único aparelho de modo a isolar um problema específico. Munido dessa ferramenta, o genealogista é capaz de demarcar a natureza da relação que pode existir entre esses elementos discursivos e não-discursivos, além de evidenciar a função estratégica do dispositivo na medida em que responde à articulação entre produção de saber e modos de exercício de poder que são dominantes em cada momento histórico.

\section{CONCLUSÃO}

\section{O lugar das instituições disciplinares na sociedade contemporânea}

Observando concretamente a realidade atual, sabemos que o poder e as práticas disciplinares, no século XXI, estão mais sofisticados e qualitativamente mais dispersos na vida social como um todo. Mas nossa perspectiva de análise neste artigo, sem desprezar esse fato, concentra-se e focaliza universos institucionalizados mais restritos, pois a atuação dos profissionais da saúde coletiva (psicólogos, terapeutas ocupacionais, assistentes sociais, médicos, psiquiatras etc.) dificilmente se ocupa com a totalidade do campo social, que é considerado um importante pano de fundo.

Nossa ação profissional é normalmente situada em contextos institucionais específicos. Nesses ambientes, notamos que continuam sendo implementadas inclusive as estratégias mais grosseiras de normalização disciplinar mapeadas por Goffman (1987) e Foucault (1999b), apesar da sofisticação trazida pela tecnologia: telefone celular, Internet, equipamentos de monitoração de lojas, empresas, ruas e praias públicas com câmeras, rastreamento via satélite, informatização do controle e gerenciamento de pessoas nos mais diversos tipos de estabelecimento.

Particularmente no que tange à saúde mental no âmbito maior da saúde coletiva, devido ao clássico descuido e falta de investimentos governamentais, continuamos com instituições nas quais vigoram práticas totalitárias tão rudimentares ainda que poderíamos considerar tais estabelecimentos verdadeiras "excrescências" não só do ponto de vista temporal, mas inclusive quanto à própria transformação e sofisticação das tecnologias de controle.

Sendo a sociedade um tecido formado por uma rede de instituições sociais, os problemas psicossociais devem ser contextualizados no plano institucional e sociopolítico nos quais emergem para serem adequadamente equacionados sob pena de permanecermos em considerações funcionalistas que apenas mascaram a realidade do poder e da política, reduzindo-os a questões de ordem "psicológica" ou "sociológica" individuais. Muitas vezes, provavelmente, o que tomamos como efeito colateral é, na verdade, o produto principal da ação institucional, apesar de todos os seus discursos altruístas, plasmados nos seus projetos oficiais.

Podemos afirmar que dominação, aumento da alienação social, adaptação sociocultural, mistificação ideológica são funções das diversas instituições sociais na sociedade burguesa capitalista. As ciências humanas emergentes nos séculos XIXeXX nasceram com esse mandato de gerenciamento das populações para a manutenção do sistema (Foucault, 1999b). Desde 
sempre, e muito antes, essa também foi a função social da religião: manutenção ideológica do sistema social, na antigüidade e no mundo medieval. Na modernidade, o controle social estatal ganhou ares de cientificidade (Foucault, 1999b).

O que nos ocupa neste estudo é a análise de instituições entendidas como elementos de um dispositivo articulador das relações entre produção de saberes e modos de exercício do poder. Por isso retomamos a descrição de determinadas instituições: aquelas que, num dado momento histórico, constituem peças na engrenagem de um tipo específico de sociedade, que Foucault (1984; 1999b) nomeou como "instituições disciplinares". Nesse sentido, o que a genealogia de Foucault nos proporciona é uma análise pragmática da nossa situação atual, haja vista que ainda vivemos numa sociedade disciplinar, pelo menos no que diz respeito a uma boa parte da vida social alijada da produção e consumo de tecnologia de ponta. A partir dos estudos que realizamos, entendemos que um elemento estrutural das instituições em geral é o descompasso e a contradição entre o plano estabelecido em seus estatutos e as práticas implementadas em seu projeto cotidiano. Essa cisão formal encontra seu sentido no fato de que o sucesso de uma instituição depende do seu aparente fracasso como uma organização formal que se dispõe a realizar alguns objetivos específicos.

Foucault (1999b) ressalta que a principal função das instituições no estrato sócio-histórico da sociedade disciplinar é de normalização, implementando práticas classificatórias, hierarquizantes, distribuindo lugares. Desse modo, o atual campo enunciativo que possibilita "ver" e "falar" algo (remetendo às práticas) aprisiona e aliena ambos os pólos (agentes institucionais dirigentes e clientela). O que uma instituição visa é controlar os desvios dos sujeitos enquanto indivíduos, esquadrinhando seus comportamentos e efetuando sobre eles uma vigilância constante. Quase poderíamos dizer que os diversos atores institucionais "não sabem o que fazem", afinal, é seu ser social que determina sua consciência e suas práticas. Sabemos que sua ação é historicamente condicionada e determinada pelas condições sociais gerais de produção e reprodução da existência.

Também é verdade que se uma instituição cumprisse o que se propõe a realizar, ela se dissolveria. $\mathrm{E}$ as instituições tendem a resistir aos processos de dissolução, por isso gastam grande parte de suas energias em esforços de automanutenção. Mas temos o direito de exigir das instituições o cumprimento do "contrato simbólico" (Costa-Rosa, 2000; 2002), questionando até que ponto os instrumentos utilizados têm alguma conexão com a possibilidade de cumprirem suas promessas.

Podemos afirmar que a institucionalização da vida do indivíduo produz um tipo de subjetividade específica trabalhando na sua formação através de práticas objetivantes e subjetivantes que incidem diretamente na sua constituição subjetiva, promovendo a explicitação de várias de suas possibilidades neuróticas, psicóticas e perversas, tal como podemos verificar em Castel (1978), Guirado (1986), Goffman (1987), Cruz (1989), Tagliavini (1990), Ferraz e Ferraz (1994), Foucault (1999b), Benelli \& Costa-Rosa (2002), Benelli (2002; 2003). Embora muitos desses autores não utilizem explicitamente a expressão "produção de subjetividade", eles caracterizam bem sua produção, destacando os efeitos iatrogênicos do processo de institucionalização de pessoas.

Os saberes psi devem abrir mão do poder de controle que Ihes foi historicamente delegado, quando se encomendava que eles gerenciassem a loucura e controlassem os distúrbios da população. Superando a mera função de mantenedores da ordem pública, renunciando à condição de instrumentos promotores de segurança pública ao administrarem a "periculosidade social" dos indivíduos desviantes, os profissionais psi podem orientar sua ação na direção de uma ética singularizante.

$\mathrm{Na}$ sociedade capitalista, as instituições metabolizam a contradição principal (capital/ trabalho) através de diversas estratégias. As relações de poder são escamoteadas e interpreta- 
das de um modo funcionalista: tendência a uma psicologização interiorizante e individualizante, ou a uma sociologização que universaliza os interesses da equipe dirigente (representante das forças hegemônicas sociais e institucionais), negação das contradições sociais reais e um processo de naturalização que elude a historicidade dos fatos (Albuquerque, 1980).

Acreditamos que seja necessário pensar as relações de poder situadas no conjunto de práticas sociais que produzem os sujeitos como corpos dóceis, adestrados e seres desejantes (Foucault, 1999b). Uma articulação pertinente dos fenômenos emergentes no contexto institucional pode ser elaborada num processo de análise institucional, procurando superar posicionamentos funcionalistas ingênuos. Pensamos que as dificuldades e problemas das instituições totais não se modificariam apenas com novos métodos e técnicas de gerenciamento institucional. A inércia do instituído tende a mover os atores institucionais na direção de receitas que prometam soluções mágicas e rápidas para seus impasses e conflitos. Assim, buscam-se reformas para manutenção tudo como está, produzindo modificações em aspectos secundários que geram somente efeitos paliativos (Baremblitt, 1998).

Seria preciso ousadia para modificar o eixo central das discussões: teríamos que problematizar o objeto institucional das diversas instituições totais, desnaturalizando, "despsicologizando", "dessociologizando" o homem que aí é processado, tomando-o como um sujeito infinitamente mais complexo e multifacetado do que a caricatura empobrecida que faz dele um personagem habitante do universo institucional totalitário.

Consideramos necessário analisar as diversas práticas institucionais (formativas, educativas, pedagógicas, terapêuticas, correcionais, socioeducativas), problematizando seus pressupostos subjacentes, procurando detectar como e até que ponto tais ações funcionam como filtros de transformação seletiva e deformante de qualquer proposta inovadora.

Trata-se mesmo de promover uma revolução conceitual: dependendo de como vemos determi- nado objeto, partimos da consideração de sua suposta natureza essencial para a produção de saberes e técnicas para trabalhá-lo. Os meios e os fins seriam então decorrentes dessa natureza presumida do objeto. É por isso que acreditamos na importância de uma análise das práticas, daquilo que fazemos no contexto institucional. $\mathrm{O}$ fazer embute em si uma teoria, um objeto, saberes e técnicas: produz subjetividade, modos de existência, sujeitos, universos de materialidade social. Tal processo pode se submeter ao sentido do processo hegemônico de produção de subjetividade, mas também pode se orientar no sentido de produções singularizadas.

Nesse sentido, Costa-Rosa (2000, p.151) estabelece alguns parâmetros importantes na composição de um determinado paradigma, que devem ser observados quando procuramos estudar e caracterizar uma determinada instituição, evitando perspectivas funcionalistas: a) concepção do 'objeto' e dos 'meios de trabalho', que dizem respeito às concepções do objeto institucional e concepção dos meios e instrumentos de seu manuseio (inclui ainda o aparelho jurídico-institucional, multiprofissional e teórico-técnico, além do discurso ideológico); b) formas de organização do dispositivo institucional: como se organizam as relações intra-institucionais, organograma, relações de poder e de saber; c) formas de relacionamento com a clientela; d) formas de seus efeitos típicos em termos de resolutividade e éticos, que inclui os fins políticos e socioculturais amplos para os quais concorrem os efeitos de suas práticas. As instituições totais podem ser inseridas num paradigma denominado asilar e podemos compreender claramente sua dinâmica ao situá-las nesse contexto (Costa-Rosa, 2000).

Muitas questões pedagógicas, psicológicas, psiquiátricas, hospitalares, da saúde coletiva, etc. podem se tornar mais inteligíveis quando enquadradas num marco institucional global. Entendemos que os problemas institucionais são também problemas sociais. Soluções técnicas muitas vezes não são suficientes para resolvê-los, pois exigem soluções políticas para sua metabolização. A política não é uma questão 
técnica (eficácia administrativa) nem científica (conhecimentos especializados sobre gerenciamento ou administração), é ação e decisão coletiva quanto aos interesses e direitos do próprio grupo social.

\section{REFERÊNCIAS}

Albuquerque, J.A.G. (1980). Instituição e poder: a análise concreta das relações de poder nas instituições. Rio de Janeiro: Graal.

Baremblitt, G.F. (1998). Compêndio de análise institucional e outras correntes: teoria e prática. $4^{\mathrm{a}}$ ed. Rio de Janeiro: Record.

Benelli, S.J., \& Costa-Rosa, A. (2002). A produção da subjetividade no contexto institucional de um Seminário Católico. Estudos de Psicologia, 19, (2), 37-58.

Benelli, S.J. (2002). O internato escolar como instituição total: violência e subjetividade. Psicologia em Estudo - UEM, 7, (2), 19-29.

Benelli, S.J. (2003). Dispositivos disciplinares produtores de subjetividade na instituição total. Psicologia em Estudo - UEM, 8, (2), 99-114.

Cabras, A. (1982). Os anjos querem ser homens: um estudo sobre a laicização de padres no Brasil. Dissertação de mestrado em Ciências Sociais, Faculdade de Filosofia, Letras e Ciências Humanas, Universidade de São Paulo.

Castel, R. (1978). A ordem psiquiátrica: a idade de ouro do alienismo. Rio de Janeiro: Graal.

Costa-Rosa, A. (1987). Saúde mental comunitária: análise dialética de um movimento alternativo. Dissertação de mestrado, Instituto de Psicologia, Universidade de São Paulo.

Costa-Rosa, A. (2000). O Modo psicossocial: um paradigma das práticas substitutivas ao modo asilar. In P.D.C. Amarante (Org.). Ensaios de Loucura \& Civilização (v.1, p.141-168). Rio de Janeiro: Fiocruz.

Costa-Rosa, A. (2002). A Instituição de Saúde Mental como dispositivo de produção de subjetividade. Assis: UNESP. Mimeografado.
Cruz, S.G.F.P. (1989). Herói ou bandido? Um estudo sobre a produção de identidade em policiais militares. Dissertação de mestrado em Psicologia Social, Pontifícia Universidade Católica de São Paulo.

Deleuze, G. (1992). Conversações. Rio de Janeiro: Editora 34.

Ferraz e Ferraz, M.G.C. (1994). Religare. Uma cartografia da fé. Tese de doutorado em Psicologia Clínica, Pontifícia Universidade Católica de São Paulo.

Foucault, M. (1982). A Vontade de saber (História da Sexualidade I). $4^{\mathrm{a}}$ ed. Rio de Janeiro: Graal.

Foucault, M. (1984). A verdade e as formas jurídicas. Cadernos da PUC/RJ: Série Letras e Artes, 6/74 (16).

Foucault, M. (1999a). História da loucura na Idade Clássica. 6a edição. São Paulo: Perspectiva.

Foucault, M. (1999b). Vigiar e punir: nascimento da prisão. $21^{\mathrm{a}}$ ed. Petrópolis: Vozes.

Foucault, M. (1999c). Microfísica do poder. $14^{\mathrm{a}} \mathrm{ed}$. Rio de Janeiro: Graal.

Goffman, E. (1987). Manicômios, prisões e conventos. $2^{\mathrm{a}}$ ed. São Paulo: Perspectiva.

Guirado, M. (1986). Instituição e relações afetivas: o vínculo com o abandono. São Paulo: Summus.

Hesse, H. (1970). Narciso e Goldmund. $4^{\mathrm{a}}$ ed. São Paulo: Brasiliense.

Hesse, H. (1980). Menino prodígio. 5a ed. Rio de Janeiro: Record.

Lautréamont, C. (1986). Cantos de Maldoror. São Paulo: Max Limonad.

Levinson, D.J., \& Gallagher, E.B. (1971). Sociología del enfermo mental. Buenos Aries: Amorrortu.

Musil, R. (1986). O Jovem Törless. Rio de Janeiro: Rio Gráfica.

Perrone-Moisés, L. (Org.) (1988). O Ateneu: retórica e paixão. São Paulo: Brasiliense. 
Pompéia, R. (1997). O Ateneu. São Paulo: Publifolha.

Rego, J.L. (1979). Doidinho. $18^{a}$ ed. Rio de Janeiro: José Olympio.

Rocha, C.L.R. (1991). Muitos são os chamados mas poucos escolhidos" - um estudo sobre a vocação sacerdotal. Dissertação de mestrado em Antropologia Social, Instituto de Filosofia, Letras e Ciências Humanas, Universidade Estadual de Campinas.

Salla, F. (2000). A retomada do encarceramento: as masmorras high-tech e a atualidade do pensamento de Michel Foucault. In F., Biroli \&
M.C. Alvarez (Orgs.). Cadernos da F.F.C. Marília: Unesp Publicações.

Tagliavini, J.V. (1990). Garotos no túnel: um estudo sobre a imposição da vocação sacerdotal e o processo de condicionamento nos seminários. Dissertação de mestrado em Ciências Sociais, Instituto de Filosofia, Letras e Ciências Humanas, Universidade Estadual de Campinas.

Trevisan, J.S. (1985). Em nome do desejo. $2^{\mathrm{a}}$ ed. São Paulo: Max Limonad.

Recebido para publicação em 20 de outubro de 2003 e aceito em 21 de outubro de 2004. 